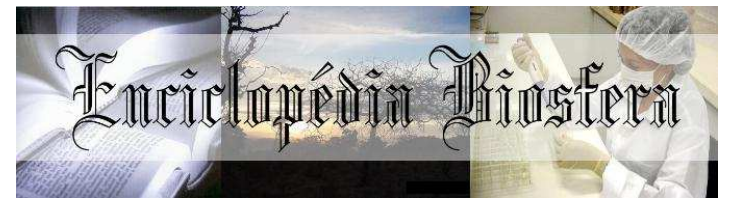

\title{
ALIENAÇÃO PARENTAL E NARCISISMO NOS VÍNCULOS FAMILIARES: ESTUDO DE CASO
}

Gabrielle Bertol de Oliveira Guilherme1, Bruna Rafaele Milhorini Greinert ${ }^{2}$, Rute Grossi Milani ${ }^{3}$

1 Psicóloga e especialista em Psicanálise: Teoria e Clínica pelo Centro Universitário

Cesumar - UniCesumar - Maringá - Pr, Brasil. (gabriellebertol@gmail.com).

2 Psicóloga e mestre em Promoção da Saúde pelo Centro Universitário Cesumar -

UniCesumar - Maringá - Pr, Brasil.

3 Profa Dra do Programa de Mestrado em Promoção da Saúde e do Programa de Mestrado em Tecnologias Limpas do Centro Universitário Cesumar - UniCesumar Maringá - Pr, Bolsista do Programa Produtividade em Pesquisa do ICETI - Instituto

Cesumar de Ciência, Tecnologia e Inovação. Brasil

\section{Recebido em: 08/04/2017 - Aprovado em: 10/06/2017 - Publicado em: 20/06/2017} DOI: 10.18677/EnciBio_2017A117

\begin{abstract}
RESUMO
Após o divórcio, quando os pais entendem que o filho é uma extensão de si, podem tornar a criança destino para suas frustrações. Na síndrome de alienação parental não é reconhecido que a criança tem o direito a uma história e sentimentos próprios, ficando presa à vida emocional do alienador, pois este não consegue perceber o filho como outro indivíduo. O objetivo deste estudo foi compreender a alienação parental sob a luz da psicanálise e sua relação com o vínculo simbiótico e narcisista entre pais e filhos. Buscou-se analisar o comportamento do pai alienador, com base no conceito de narcisismo de Freud. Trata-se de um estudo de caso, com abordagem qualitativa, em que foi realizada análise documental de relatos e laudos resultantes de avaliações feitas pelo Apoio Especializado em Psicologia do Fórum de uma comarca no interior do estado do Paraná. Foram analisados: histórico familiar, queixa judicial, sintomas apresentados pelo infante, comportamento dos pais e desenlace do caso. Observou-se que nos dois casos os genitores estavam voltados apenas para os seus interesses após a separação, as crianças encontravam-se em momento de fragilidade e se voltaram aos pais alienadores apresentando comportamentos para agradá-los, desprezando a genitora. Concluiuse que há encontro daquilo que se entende por narcisismo na psicanálise e o comportamento egoísta dos pais que alienam os filhos não só do convívio com o outro genitor, bem como desconsideram a individualidade destas crianças.
\end{abstract}

PALAVRAS-CHAVE: vulnerabilidade infantil; violação de direito da criança; violência psicológica. 


\title{
PARENTAL ALIENATION AND NARCISSISM IN FAMILIAR BONDS: CASE STUDY
}

\begin{abstract}
When parents, after the divorce, understand that their kid is an extension of themselv es, they can make the child the target to their frustation. Parental alienation syndrom e doesn't recognize the child's right to having a history and his/her own feelings, leavi $\mathrm{ng} \mathrm{him/her} \mathrm{stuck} \mathrm{to} \mathrm{the} \mathrm{alienator's} \mathrm{emotional} \mathrm{life,} \mathrm{since} \mathrm{the} \mathrm{last} \mathrm{one} \mathrm{can't} \mathrm{acknowledg}$ e their child as another subject. The goal for this study was to comprehend parental al ienation under the light of psychoanalysis and their relationship to the symbiotic and narcissistic bond between parents and their children. We seeked to analyze the behavior of the alienator parent, based on the oncept of Freud's narcissism and understand parental alienation under the perspective of psychoanalysis. It is a case study, with a qualitative approach, in wich it was made a documentary analysis of reports that resulted from assessment's made by the Forum's Specialized Support in Psychology in a county in the State of Paraná. We analyzed family history, judicial complaints, symptoms showed by the infant,he parents' behavior and the case's outcome.It was noticed that,in both cases, the fathers only cared for their own interests after the divor ce, the kids were found in a fragile moment and reached for their alienator parents by presenting behaviors that would please them, forgetting their mothers. Therefore, we conclude that there is an encounter between what is understood as narcissism in psychanalysis and the selfish behavior of the parents that alienate their children not only from living with their other parent, but also by overlooking their individuality.
\end{abstract}

KEYWORDS: child vulnerability; Violation of the right of the child; psychological violence.

\section{INTRODUÇÃO}

A implantação da lei n 12.318 em 2010 dentro do Código Civil Brasileiro, que define legalmente o que é a Alienação Parental e assim a torna passível de responsabilização jurídica, visa amparar crianças e adolescentes vítimas de alienação parental, uma vez que a prática de alienar pode acarretar prejuízos ao desenvolvimento infantil (DANTAS et al., 2016).

A vivência da alienação parental por crianças e adolescentes tem se tornado algo cada vez mais presente na realidade das famílias, resultado do aumento do número de divórcios e separações (STOCKER et al., 2014). Desta forma, a lei de Alienação Parental trouxe à luz da justiça muitos casos de pais impedidos de terem uma convivência satisfatória com seus filhos após a dissolução do casamento (DANTAS et al., 2016). A criação da lei se deu também pela percepção do judiciário de que o que acontecia entre pais e filhos não era somente uma questão familiar passageira e sim um problema.

Pela referida Lei, a prática da Alienação Parental se define da seguinte forma:

Art. $2^{\circ}$ Considera-se ato de alienação parental a interferência na formação psicológica da criança ou do adolescente promovida ou induzida por um dos genitores, pelos avós ou pelos que tenham a criança ou adolescente sob a sua autoridade, guarda ou vigilância para que repudie genitor ou que cause prejuízo ao estabelecimento ou à manutenção de vínculos com este (BRASIL, 2010). 
Como formas de inibir tal ato a lei brasileira prevê a inversão da guarda, multa e até mesmo a suspensão da autoridade parental, entre outros. Apesar de a lei surgir somente em 2010, já em 1980, GARDNER (1998), psiquiatra americano, verificou que este tipo de comportamento se perpetuava nas famílias da época. Inicialmente ele definiu a Alienação Parental pela implantação de falsas informações acerca do outro pai na mente da criança, visando o afastamento como método de vingança. Portanto, após a separação um dos genitores, inconformado com o término do relacionamento e de modo a vingar-se do outro par, passa a implantar informações no emocional da criança para que ela rejeite o pai ou a mãe. GARDNER (1998) percebeu que a maioria das alienadoras eram mães que após o divórcio, não permitiam o contato dos filhos com os pais e que apresentavam quadros comportamentais muito parecidos, principalmente a difamação do pai, a inclusão de falsas lembranças, o boicote a visitas e passeios, entre outros. Segundo STOCKER et al. (2014), esse comportamento acontece quando há uma separação legal do casamento, mas não há uma ruptura afetiva por um dos cônjuges.

$\mathrm{Na}$ época das descobertas de GARDNER (1998) ele definiu uma escala de sintomas que caracterizavam a Síndrome de Alienação Parental (SAP) em leve, moderada e severa. No primeiro estágio a criança ainda mantém contato com o pai alienado e no último denigre e recusa completamente a presença ou a menção do genitor. O autor ainda salienta que embora por muito tempo a mãe fosse considerada a principal alienadora, hoje este papel pode ser atribuído a ambos os pais e também a outros familiares. De acordo com BROCKHAUSEN (2011) o alienador pode fazer uso de manipulações e táticas psicológicas explícitas ou implícitas para persuadir a criança, sendo que muitas vezes nem o próprio genitor tem consciência do mal causado aos filhos.

Como os casos de Alienação Parental envolvem a questão jurídica da família, observa-se que muitas vezes as famílias se despersonificam diante desses casos, atribuindo ao juiz o papel de decidir o destino de todos. OLIVEIRA \& BRITO (2013) argumentam sobre o fato de que os indivíduos se tornaram apenas personagens de suas histórias, delegando à justiça a responsabilidade de decidir o destino dos filhos.

Nesta perspectiva, resgatar a individualidade dos pais e a posição destes como autores de suas próprias histórias pode dar ao ex-casal melhores condições para superar o divórcio, sem que haja uma vitimização de ambos os lados e consequentemente um enfraquecimento dos laços afetivos entre pais e filhos. Segundo FERREIRA et al. (2016), é preciso indagar à família sobre as responsabilidades como ambiente primário para o crescimento de um novo ser.

LEVY \& GOMES (2011) introduzem a ideia de que o rompimento do casamento provoca uma ferida narcísica e que "o ressentimento e o ódio pela perda das ilusões depositadas no casamento ou no parceiro provocam um desejo de aniquilar o outro" (p.47). Diante disso é feita a leitura deste panorama conjugal sob a ótica freudiana, na qual FREUD (1914) define o narcisismo como o complemento libidinal do egoísmo do instinto de auto conservação, ou seja, aquela porção de afeto individual que preserva o sentimento de valoração, que protege o sujeito das dores da realidade, mas que também pode aliená-lo do mundo.

Na dinâmica freudiana da libido narcísica secundária, quando o eu investe afeto em um objeto, ele deposita sua energia e ao mesmo tempo se esvazia dela (FREUD, 1914). Neste sentido, um bom exemplo é o caso das relações amorosas, nas quais há um investimento afetivo intenso que torna o ser amado perfeito, já o 
amante por sua vez tem a sensação de que ele próprio não possui valor, pois já se esvaziou da sua energia libidinal. O mesmo ocorre em um casamento fracassado, todo o investimento afetivo feito no parceiro acaba voltando para o indivíduo e isso resulta em um grande sofrimento e sentimento de desvalor.

Para FREUD (1914), a pessoa que vivencia uma frustração amorosa se depara com a seguinte situação "um forte egoísmo protege contra o adoecimento, mas afinal é preciso começar a amar, para não adoecer, e é inevitável adoecer, quando, devido à frustração, não se pode amar". Tendo em vista a alienação parental, pode-se propor um paralelo de que após a separação todo o investimento libidinal retorna ao ego, ocorre então uma necessidade de se encontrar um objeto novo, mas o indivíduo acaba adoecendo, pois está impossibilitado de amar devido a frustração.

Portanto, o divórcio pode promover nos indivíduos narcísicos uma regressão ao narcisismo infantil, fonte de sentimentos de onipotência, como forma de preservar o autovalor $e$ isso faz com que se sinta dominante do outro, e negando a individualidade, perceba o antigo companheiro e a criança como uma extensão de si. A criança é fruto do desejo dos próprios pais, portanto, é nos filhos que os pais encontram um refúgio para se proteger da dureza da realidade, da sua mortalidade e limitações, revivendo com a criança seus sentimentos narcísicos primitivos. Nesta mesma ótica, em um estudo realizado por DAMIANI \& RAMIRES (2016), que visou investigar as características de estrutura de personalidade de pais e mães envolvidos no conflito da alienação parental, constatou-se a presença de defesas primitivas, intensa ansiedade de separação, predominância de vínculos simbióticos, dificuldade de discriminação e percepção inadequada do outro.

Por outro lado, é preciso considerar que os conflitos derivados da relação entre os genitores expõem a criança às discórdias conjugais, gerando repercussões para o desenvolvimento dos filhos (GOULART et al., 2015). Crianças expostas a violência interparental, seja sob forma de agressão física ou psicológica, vivenciam a violação de seus direitos. Segundo ALMEIDA et al. (2013) a violência contra a criança pode manifestar-se de forma direta e indireta, ou seja, quando ocorre diretamente com a criança, ou quando esta presencia cenas de agressão sofrida por outro membro da família. Em ambos os casos sua saúde física e mental pode ser prejudicada.

Uma vez que a SAP ocorre com frequência em famílias que buscam o judiciário a fim de resolver questões de divórcio e disputa de guarda dos filhos (LUZ et al. 2014), o objetivo deste estudo foi compreender a alienação parental sob a luz da psicanálise e sua relação com o vínculo simbiótico e narcisista entre pais e filhos. Para isso, foram analisados dois casos de Alienação Parental atendidos pelo departamento de psicologia de uma comarca do interior do Paraná.

\section{MATERIAL E MÉTODO}

Trata-se de um estudo de caso, com abordagem qualitativa, em que foi realizada análise documental de dois laudos resultantes de avaliações feitas pelo Apoio Especializado em Psicologia do Fórum de uma comarca no interior do estado do Paraná. A pesquisa documental foi realizada do dia 27 ao dia 30 de abril de 2015, no departamento referido, através da seleção de documentos específicos, ou seja, dois laudos que melhor atendiam aos interesses da pesquisa, a organização do material e posteriormente a discriminação de dados para análise. Esta pesquisa foi aprovada pelo Comitê de Ética do Centro Universitário de Maringá, sob o Protocolo nำ 1.009.258. 
Foram escolhidos dois casos avaliados pelo referido departamento, nos quais havia a específica denúncia de Alienação Parental por parte de um dos genitores. Em ambos os casos os pais estavam separados e a genitora acusava 0 pai de estar praticando a alienação e por isso estavam afastadas do convívio com a criança. A seguir é apresentada uma breve caracterização da família, e devido ao cuidado ético, optou-se pela escolha de um nome fictício para cada um dos membros.

Caso 1: a Família Silva era composta por João, 33 anos, Maria, 35 anos e a criança, Carlos com 12 anos. Os pais estavam separados há seis anos e após a separação a criança residia com a mãe, a genitora adoeceu em decorrência do falecimento de um parente e o filho precisou residir com o pai. Com o decorrer do tempo, a mãe foi perdendo o contato com a criança a ponto desta se negar a vê-la e apresentar muito medo do contato.

Caso 2: a família Almeida era composta por Paulo 45 anos, Clarice 41 anos e a criança Rafael com 9 anos de idade. Os genitores estavam separados há cerca de dois anos e já constituíam novo relacionamento. Após a separação, a criança passou a residir com o pai e os contatos foram ficando escassos com a mãe.

Para a coleta de dados foram utilizados os laudos decorrentes das avaliações e elaborado uma ficha na qual constavam os dados de sexo, idade, histórico familiar, queixa judicial, sintomas apresentados no infante, comportamento dos pais e desfecho do caso.

Após a coleta de dados, estes foram submetidos à análise e discussão. $O$ procedimento utilizado foi a análise de conteúdo, que segundo BARDIN (2010), permite ao pesquisador ir além da compreensão simples da realidade e objetiva uma investigação minuciosa das comunicações.

\section{RESULTADOS E DISCUSSÃO}

Com base nos dados coletados, os resultados serão apresentados em três categorias:

1. O comportamento dos pais em relação ao rompimento do vínculo;

2. O comportamento da criança e os vínculos familiares;

3. Desenlace, consequências e intervenções dos casos;

\section{O comportamento dos pais em relação ao rompimento do vínculo}

No caso de ambas as famílias analisadas há o relato de traição por um dos cônjuges, fato que tornou o casamento insustentável, talvez pela perda da ilusão e dos sentimentos que fundaram a família (LEVY \& GOMES, 2011). Nota-se no discurso dos genitores traídos que há uma mágoa velada que permanece mesmo após algum tempo do divórcio e estabelecimento de nova união. Além disso, essa amargura remete à figura do terceiro excluído que FREUD (1914) aponta e como uma ferida narcísica infantil dos tempos da passagem pelo Complexo Edipiano.

O presente estudo corrobora tal afirmativa mediante a análise dos dados levantados sobre da família Almeida, em que a genitora revelou que em certo dia ao ver Carlos com o pai e a atual namorada juntos no centro da cidade, notou que o filho caminhava sozinho atrás do casal. Ao ver esta cena, entendeu que o filho estaria sendo excluído pelo casal, gerando um sentimento de revolta, que resultou em uma grave discussão.

Nota-se, portanto, que a mãe ao ver tal cena depreendeu que o filho estaria 
se sentindo excluído e possivelmente agiu projetivamente, ou seja, ela sentiu-se excluída da cena, mas creditou o sentimento ao filho. Percebe-se a intensidade da dor emocional quando ela relata que foi tirar satisfação com o ex-cônjuge e a conversa tornou-se uma discussão e posteriormente uma briga séria na frente da criança.

Na família Silva vê-se que a entrada da terceira pessoa no relacionamento é o ponto crítico da história, a ferida emocional que surge disto, afronta não somente a genitora como também o restante dos familiares. A mãe de Carlos, Maria, sentiu-se muito afrontada com a traição do seu esposo, pois foi com uma amiga da família, o que resultou no fim do casamento. Além disso, o laudo identifica que a atual esposa do ex-marido por inúmeras vezes a provocou com a situação, e isto era fonte de brigas e discussões. O laudo relata que a família extensa tentou ajudar o casal a melhorar o relacionamento, mas não conseguiram e que o surgimento desta terceira pessoa atrapalhou a vida de todos devido ao comportamento manipulador e provocativo da nova esposa do genitor.

Em ambos os casos os relacionamentos foram permeados por traições e marcas muito profundas geradas pela dor da perda, tanto do cônjuge como da vida emocional que compartilhavam. Quando se desfaz a ilusão de ambiente emocional comum do casal o rancor é esperado. De acordo com LEVY \& GOMES (2011) as pessoas com intensas necessidades narcísicas tendem a negar a diferença, a existência do outro com suas qualidades e defeitos. Portanto, entende-se que quando há indivíduos com um emocional bem estruturado é possível adoecer após a separação, mas ao longo do tempo conseguir se reestruturar novamente. Nestes casos percebe-se que os dois cônjuges não elaboraram o final do relacionamento e não possuem o entendimento de que o outro tem uma vida própria, ficando presos às suas próprias feridas.

Aparentemente não está em jogo a perda do outro, pois todos constituíram novos relacionamentos, mas sim a nova perda da ilusão narcísica, de sentimentos onipotentes e complementares, vividos nos primórdios da infância. Com as traições há perda daquilo que MOGUILLANSKY \& NUSSBAUM (2011) salientam como fator fundante do vínculo amoroso, 0 sentimento de segurança, confiança, pertencimento, reciprocidade e principalmente propriedade.

Portanto, ambos adoecem, mas aquele que tenta alienar o filho do outro genitor se sente tão fragilizado que usa a criança como forma de se empoderar e justificar seu comportamento. Presume que o filho se sente tão magoado ou ferido quanto ele e encontra na criança uma forma de angariar forças contra o outro. Este comportamento do pai alienador pode ser explicado pelo mecanismo de projeção, em que o sujeito expele de si um conteúdo inconsciente e deposita no outro. $\mathrm{O}$ indivíduo lança para o mundo externo um conteúdo que não reconhece como seu, pois Ihe causa muita angústia (LAPLANCHE \& PONTALIS, 2001). No caso da alienação parental, o pai projeta a dor de sua rejeição na criança, por não suportar este conteúdo como sendo seu.

Nos casos analisados foi encontrada uma passagem que demonstra o quanto o pai que aliena a criança encontra-se fechado para perceber a realidade dos fatos. No caso da família Almeida, o irmão mais velho de Rafael relatou que diversas vezes flagrou o pai denegrindo a imagem da mãe para a criança no momento de colocá-la para dormir. Em relação a família Silva, Carlos se recusava em visitar a mãe, em seu discurso notavam-se frases ditas com frequência pelo pai, como o fato de que a mãe era louca e por isso não queria passar os finais de semana com a mesma. Além disso, a cada negativa da criança em visitar a mãe 
questionava a madrasta se estava se comportando como ela queria, mesmo estando na frente de familiares e até do conselho tutelar. Segundo SERAFIM \& SAFFI, (2012), a criança alienada manifesta tais comportamentos por estar contaminada com as prerrogativas do genitor alienante, nem sempre tendo consciência de seus atos e ações.

Nesses trechos percebe-se a manipulação dos pais no comportamento da criança. No caso da família Silva o genitor e a madrasta utilizam da expectativa da criança em ser amada e aceita para influenciar seu comportamento. Já na família Almeida, percebe-se que o pai fazia uso de um momento em que podia dar atenção especial ao filho, a hora de dormir, como forma de se aproximar e difamar a mãe, ou seja, aparentemente houve a associação de um momento prazeroso entre pai e filho com a recusa da mãe. Para as crianças funciona como uma troca, ou seja, para ganhar a atenção do pai é preciso excluir a mãe do relacionamento afetivo. Do ponto de vista narcísico, faz-se a união entre genitor e a criança, como no narcisismo primário e exclui-se tudo aquilo que é externo.

Sobre o comportamento dos pais durante a avaliação foi descrito que o pai de Carlos era carismático, preocupado em contar os episódios ruins que passou enquanto era casado e relatar o quando a ex-esposa seria desequilibrada mentalmente, entretanto, não negou que teve outro envolvimento amoroso durante o casamento. Já o pai de Rafael mostrou-se magoado com a separação, porém controlou-se emocionalmente, pareceu ter um discurso pronto acerca do assunto, explicou que depois da separação contraiu dívidas e por isso não podia comprar roupas para o menino.

Em ambos os relatos se percebeu um posicionamento de vítima por parte do alienador, também há a manutenção do discurso difamatório contra a ex-esposa para os profissionais que atenderam o caso. Com esse recorte da avaliação compreende-se que não há um entendimento por parte do alienador de que faz algo errado, há um sentimento de vitimização e fragilidade e ele compreende aquilo que faz (alienar o filho) como se estivesse defendendo a si e à criança das vivências desagradáveis com o antigo companheiro. Tal informação é concordante com os achados de BROCKHAUSEN (2011), pois na maioria das vezes o pai alienador utiliza-se de manipulações consciente e inconscientemente para persuadir o filho, sem perceber o mal causado à criança.

Conclui-se que as atitudes dos pais na dissolução da relação têm influência no comportamento dos filhos, pois a criança ainda está envolvida nas expectativas paternas e se identifica com a fragilidade emocional em que os pais se encontram. Como explicado por MOGUILLANSKY \& NUSSBAUM (2011), percebe-se que a perda da ilusão narcísica é o ponto de sofrimento da separação, onde a frustração impulsiona a manipulação da criança para gerar força para o ego magoado e fragilizado.

\section{O comportamento da criança e os vínculos familiares}

Nos casos apresentados notou-se o comportamento alienado das crianças e as consequências da manipulação mental. Conforme os registros sobre Carlos, averiguou-se que a criança apresentava respostas prontas e negativas em relação à mãe, rejeição, falta de ambivalência e comportamento sem emoções no tocante à relação maternal. Depois da separação tornou-se um menino agressivo, medroso e "sem vida". Os familiares o consideram fechado, com medo de ir sozinho aos lugares e até de falar. O pai relatou que por volta dos oito, nove anos, depois que 
veio para sua casa, o menino passou a apresentar enurese e fezes durante o sono e que isso durou cerca de seis meses.

A família desempenha um papel essencial como cuidadora, pois sua presença interfere diretamente no processo de formação da educação e socialização de seus integrantes (OLIVEIRA \& ROCHA, 2015). Desta forma, 0 comportamento da criança ou adolescente é resultante do desenvolvimento biológico e social, sendo o último, reflexo dos cuidados e das relações estabelecidas na criação. Os pais são figuras importantes e, mesmo na falta destes, a forma como as pessoas exercem os cuidados terá reflexo no decorrer do amadurecimento emocional do indivíduo.

DESSEM \& POLONIA (2007) explicam que os laços que se formam nas famílias são o suporte para enfrentar as dificuldades da vida cotidiana, pois há apoio social e psicológico entre os familiares. Quando situações difíceis acontecem, ativa-se a rede de apoio da família e essa rede alimenta o sentimento de pertença, a busca de soluções e atividades compartilhadas entre os membros. Também é a partir das figuras parentais que a criança constrói a sua autoestima, autoconceito e as bases de como irá se relacionar com outras pessoas na área social.

A criança ou adolescente que recebe um suporte adequado dentro do núcleo familiar tem mais chances de um desenvolvimento emocional, cognitivo e social sadios. DESSEN \& POLONIA (2007) também esclarecem que por outro lado, os vínculos afetivos ruins podem dificultar o desenvolvimento, provocando problemas de ajustamento social da criança. Na Alienação Parental entende-se que o pai que a pratica encontra-se narcisicamente voltado para si e por isso, incapaz de perceber as necessidades da criança ou do adolescente. Compreende-se que não há um ambiente emocional e social sadio para que o vínculo familiar se desenvolva satisfatoriamente.

Dentre os comportamentos apresentados pela criança alienada, destacamse a difamação e ódio contra o pai alvo; racionalizações fracas, absurdas ou frívolas para justificar tal depreciação e ódio; falta de ambivalência usual sobre o pai alvo; apoio ao pai favorecido no conflito; falta de culpa quanto ao tratamento dado ao genitor alienado; uso de situações e frases emprestadas do pai alienante; difamação não apenas do pai alienado, mas direcionada também à família e aos amigos do mesmo (SERAFIM \& SAFFI, 2012). Os achados do presente estudo corroboram tal afirmativa, pois ante a vivência da alienação parental, Rafael passou a apresentar comportamentos de difamação e ódio contra a mãe e também ao seu companheiro atual, demonstrando apoio total ao pai, falta de culpa quanto ao tratamento dado à mãe, o uso de frases emprestadas do pai para justificar suas escolhas, assim como um tratamento preconceituoso dado ao padrasto.

O pai alienador enreda a criança em seu narcisismo e esta passa a agir como uma extensão das vontades deste. Não há a percepção da existência do outro pai, das suas qualidades, pois, a criança passa a repetir aquilo que o narcisismo paterno considera o correto. O narcisismo remete a onipotência, a não perceber a realidade ou o outro, por isso a criança não sente culpa ao desprezar o outro pai. Somente mais velho, quando conseguir se constituir como um indivíduo diferente do pai alienador é que talvez perceba a existência do pai alienado de forma mais real.

A infância é um dos períodos mais vulneráveis do desenvolvimento humano, devido a inocência e imaturidade própria da criança. Quando os pais falham na tentativa de protegê-la, expondo-a a situações conflituosas, as consequências em seu desenvolvimento podem se estender por toda a vida 
(XIMENES NETO et al., 2013). De acordo com GREINERT et al. (2016), o relacionamento conturbado na família e a separação dos pais são fatores adversos associados a manifestação da depressão infantil. Nota-se que o comportamento da criança é fruto do relacionamento familiar. Nesta perspectiva, DESSEN \& POLONIA (2007) advertem que algumas famílias não possuem condições para ofertar a criança suporte emocional para seu desenvolvimento saudável. No caso da alienação parental, questiona-se a saúde mental destes pais, necessária para o pensar, educar e exercer a paternidade.

A partir das ilustrações percebe-se que em ambos os casos os comportamentos indicativos de sofrimento emocional das crianças teve relação direta com as relações familiares rompidas e a dificuldade dos pais em estabelecer vínculos sadios com os filhos após a separação. No caso da Alienação Parental, pode-se entender que há estresse, insatisfação familiar e incongruência nas atitudes dos pais em relação à criança. DESSEN \& POLONIA (2007) salientam que tais aspectos favorecem parentalidade inadequada e com consequências para a criança, com isso, constata-se que a Alienação Parental é um fenômeno das relações familiares, na qual a maior prejudicada é a criança enquanto indivíduo em desenvolvimento.

\section{Desenlace, consequências e intervenções dos casos}

Em ambos os casos as mães conquistaram alguns avanços na relação com o filho com ajuda e intervenção dos serviços que receberam do município e do estado, além da regularização judicial das visitas. No caso da família Silva a mãe era totalmente privada do convívio com Carlos, somente depois de dois anos a criança começou a aceitar a mãe e passar os finais de semana a cada 15 dias com ela. Entretanto, os atritos com o ex-cônjuge continuaram e a criança ainda apresenta grande resistência em demonstrar afeto para a mãe. A família Almeida teve avanços e retrocessos, pois a criança inicialmente desejou retornar ao convívio diário com a mãe e passou a ter atendimento psicoterapêutico. Posteriormente, ambos os pais passaram a fazer campanha difamatória um contra o outro. Rafael passou a apresentar comportamentos manipuladores e recebia regalias que não condiziam com sua idade.

Em relação aos atendimentos psicoterápicos, apenas Rafael teve acesso por mais tempo e os pais foram orientados frequentemente. No caso de Carlos o pai boicotava as sessões, não levando a criança ou acusava o profissional responsável por não saber como direcionar a psicoterapia. Como a criança era muito manipulada pelo pai optou-se por suspender os atendimentos. A guarda permaneceu com o genitor, pois a mãe solicitava apenas as visitas quinzenais. Segundo FIGUEIREDO \& MOTTA (2014), para que as intervenções realizadas pelo psicólogo sejam eficazes, é preciso que a família dê continuidade ao processo desencadeado pelas consultas, atuando como um ambiente saudável, estável ou suficientemente bom que seja capaz de conter as angústias da criança. Para que a psicoterapia seja efetiva, os pais devem estar empenhados no processo de cura da criança e no caso de Carlos, o pai por não ter aparato emocional, não conseguia perceber a importância dos atendimentos para o menino.

Entende-se que para haver tratamento psicológico é necessário que o indivíduo reconheça seu sofrimento e o sofrimento do outro. Na prática de alienar, o pai alienador não distingue que o filho é outro indivíduo e está causando sofrimento a ele, pois está preso ao seu narcisismo. Desta forma, o processo psicoterapêutico torna-se ineficaz, uma vez que o próprio pai não reconhece o sofrimento vivenciado 
pelo filho devido a alienação.

FONSECA (2006) explica que quando os sintomas são leves há a possibilidade mais fácil de reversão da alienação, porém quando já estão instalados, as chances de reversão são de apenas $5 \%$ nos casos infantis. Adolescentes conseguem lidar melhor com a situação, pois já estão mais independentes emocionalmente dos pais. Além disso, a autora destaca que os meninos de oito a onze anos apresentam mais sintomatologia quando separados do pai, pois estão em uma fase da vida em que sofrem mais com a ausência da figura paterna.

Segundo COSTA (2011), os pais que são privados do contato com seus filhos precisam persistir na tentativa de resgatar o vínculo com a criança, mesmo sentindo a rejeição constante, humilhante e desmoralizante. Em ambos os casos analisados, as mães foram orientadas das dificuldades que encontrariam, sentiramse fragilizadas e sugeriram abandonar o processo. Apesar da desesperança notada a respeito das mães, o trabalho psicoterapêutico de orientação aos pais visou salientar os avanços já vivenciados no relacionamento com os filhos e que era uma questão de tempo para se reestabelecer o vínculo afetivo. Notou-se que nos processos judiciais, principalmente os de família, há um desgaste emocional dos indivíduos, pois há a expectativa de solução rápida. O judiciário muitas vezes não pode abarcar os desejos de todos e mais uma vez o narcisismo sai ferido nessas situações.

\section{CONCLUSÕES}

Esta pesquisa buscou compreender a alienação parental sob a luz da psicanálise e sua relação com o vínculo simbiótico e narcisista entre pais e filhos, por meio da teoria freudiana. As análises dos casos avaliados para fins judiciais revelaram que há ligação entre o narcisismo dos pais e a manipulação da criança como forma de angariar forças para reestruturar o ego ferido.

A presente pesquisa torna-se relevante ao analisar os vínculos afetivos que permeiam a relação dos genitores e o comportamento da criança que vivencia a síndrome da Alienação Parental. É preciso considerar que as feridas emocionais dos pais quanto à dissolução da relação conjugal podem influenciar o comportamento dos filhos, ao mesmo tempo em que revelam um comprometimento afetivo dos pais, necessário para o pensar, educar e exercer a paternidade.

Além disso, há poucos trabalhos que remetem a uma reflexão profunda do que se passa nas dinâmicas familiares adoecidas, ficando geralmente presas apenas ao efeito e causa do comportamento alienante. Nota-se a necessidade de pesquisas relacionadas ao tema com outros familiares que podem praticar a alienação parental, como avós e tios, bem como conhecer melhor o papel do padrasto ou madrasta no cenário alienador. A pesquisa contribui para a prática tanto dos profissionais que fazem a avaliação destes casos de família, bem como remete a outros horizontes o entendimento dos atores do direito, como Juízes, Promotores e Advogados das nuances da Alienação Parental.

\section{REFERÊNCIAS}

ALMEIDA, A. A., MIRANDA, O. B., \& LOURENÇO, L. M. Violência doméstica/intrafamiliar contra crianças e adolescentes: uma revisão bibliométrica. Gerais: Revista Interinstitucional de Psicologia, v. 6, n. 2, 298-311, 2013. Recuperado em 04 de abril de 2017, de http://pepsic.bvsalud.org/pdf/gerais/v6n2/v6n2a11.pdf. 
BARDIN, L. Análise de conteúdo. São Paulo: Edições 70, 2010.

BRASIL. Lei 12.318, de 26 de agosto de 2010. Dispõe sobre alienação parental e altera o art. 236 da Lei no 8.069, de julho de 1990. Diário Oficial da União, Brasília, DF, 27 ago. 2010. Disponível em: <http://www.planalto.gov.br/ccivil_03/_Ato20072010/2010/Lei/L12318.htm.> Acesso em: 31 de março de 2017.

BROCKHAUSEN, T. (2011) SAP e psicanálise no campo psijurídico: de um amor exaltado a um dom do amor. Dissertação de Mestrado, Instituto de Psicologia, Universidade de São Paulo, São Paulo. Recuperado em 31 de março de 2017, de http://www.teses.usp.br/teses/disponiveis/47/47133/tde-16042012162324/pt-br.php.

COSTA, A. L. F. A morte inventada: depoimentos e análise sobre a alienação parental e sua síndrome. Estudos de Psicologia (Campinas), v. 28, n. 2, p. 279281, 2011. DOI: 10.1590/S0103-166X2011000200015.

DAMIANI, F., \& RAMIRES, V. R. R. Características de Estrutura de Personalidade de Pais e Mães Envolvidos no Fenômeno da Alienação Parental. Interação em Psicologia, Curitiba, v. 20, n. 2, 2016. DOI: 10.5380/psi.v20i2.32693.

DANTAS, E. G. M. et al. Alienação parental frente à lei 13.058: a formação de uma nova perspectiva familiar. Caderno de Graduação - Ciências Humanas e Sociais - UNIT, v. 3, n. 2, 241-250, 2016. Recuperado em 12 de maio de 2017, de $<$ https://periodicos.set.edu.br/index.php/cadernohumanas/article/view/2543>.

DESSEN, M. A., \& POLONIA, A. C. A família e a escola como contextos de desenvolvimento humano. Paidéia (Ribeirão Preto), v. 17, n. 36, p. 21-32, 2007. DOI: $10.1590 /$ S0103-863X2007000100003.

FERREIRA, S. M., BOREGAS, F. C. B., GREINERT, B. R. M., CORTEZ, D. A. G., \& MILANI, R. G. O empoderamento dos pais na educação e nos cuidados dos filhos: contribuições teóricas. Cinergis, v. 17, n. 3, p. 239-244, 2016. DOI: 10.17058/cinergis.v17i3.8060.

FIGUEIREDO, P. C. \& MOTTA, I. F. Resgatando o lugar de pais: uma proposta de promoção de saúde mental. Psicologia, Saúde \& Doenças, Lisboa, v. 15, n. 1, p. 47-59, 2014. DOI: 10.15309/14psd150106.

FONSECA P.M.P.C. Síndrome de alienação parental. Revista Pediatria da Faculdade de Medicina da USP, v. 28, n 3,162-8, 2006. Recuperado em 04 de abril de 2017, de http://www.egov.ufsc.br/portal/sites/default/files/anexos/32874-40890-1PB.pdf.

FREUD, S. Introdução ao narcisismo. Rio de Janeiro: IMAGO, 1914.

GARDNER, R. A. Recommendations for dealing with parents who induce parental alienation syndrome in their children. Journal of Divorce \& Remarriage, v. 28, n. 
3/4, p. 1-21, 1998. Recuperado em 31 de março de 2017, de https:/www.fact.on.ca/lnfo/pas/gardnr98.htm.

GOULART, V. R., WAGNER, A., BARBOSA, P. V., \& MOSMANN, C. P. Repercussões do Conflito Conjugal para o Ajustamento de Crianças e Adolescentes: Um Estudo Teórico. Interação em Psicologia, v. 19, n. 9, p. 147-159, 2015. DOI: 10.5380/psi.v19i1.35713.

GREINERT, B. R. M., SOUZA, A. C. P. R., SILVA, N. B., FREITAS, R. K., \& MILANI, R. G. Sintomas depressivos em escolares: estudo exploratório em um serviço escola. Enciclopédia Biosfera, Centro Científico Conhecer - Goiânia, v.13 n.24; p. 1505, 2016. DOI: 10.18677/EnciBio_2016B_139.

LAPLANCHE, J.; PONTALIS, J.B. Vocabulário da Psicanálise. $4^{\circ}$ ed. São Paulo: Martins Fontes, 2001.

LEVY, L. \& GOMES, I. C. Relações amorosas: rupturas e elaborações. Tempo psicanalítico, v. 43, n. 1, p. 45-57, 2011. Recuperado em 29 de março de 2017, de http://pepsic.bvsalud.org/scielo.php?script=sci_arttext\&pid=S010148382011000100 003.

LUZ, A. F., GELAIN, D., \& LIMA, L. R. Reflexões sobre alienação parental em um projeto de mediação de conflitos. Revista Psicologia e Saúde, v. 6, n. 2, p. 96-103, 2014. Recuperado em 04 de abril de 2017, de <http://pepsic.bvsalud.org/scielo.php?script=sci_arttext\&pid=S2177-

093X2014000200012\&lng=pt\&nrm=iso>.

MOGUILLANSKY, R. \& NUSSBAUM, S. L. Psicanálise Vincular - teoria e clínica. Vol.1: Fundamentos teóricos e abordagem clínica do casal e da família. São Paulo: Zagodoni, 2011.

OLIVEIRA, C. F. B., \& BRITO, L. M. T. Judicialização da vida na contemporaneidade. Psicologia ciência e profissão, Brasília, v. 33, n. spe, p. 7889, 2013. Recuperado em 04 de abril de 2017, de http://www.scielo.br/scielo.php?script=sci_arttext\&pid=S1414-98932013000500009.

OLIVEIRA, E. A. R.; ROCHA, S. S. O cuidado cultural às crianças na dinâmica familiar: reflexões para a Enfermagem. Revista Interdisciplinar, v. 8, n. 1, p. 227233, 2015. Recuperado em 04 de abril de 2017, de http://revistainterdisciplinar.uninovafapi.edu.br/index.php/revinter/article/view/302/pd f_198.

SERAFIM, A.P. \& SAFFI, F. Psicologia e práticas forenses. Barueri, SP: Manole, 2012.

STOCKER, C.; WEBER, E. R.; GRANDO, P.; BASSETO, A. D. A implicação do divórcio emocional no processo da alienação parental. Akrópolis Umuarama, v. 22, n. 2, p. 139-152, jul./dez. 2014. Recuperado em 04 de abril de 2017, de http://revistas.unipar.br/index.php/akropolis/article/view/5580/3163. 
XIMENES NETO, F. R. G., SANTOS, M. P. S., SAMPAIO, J. J. C., OLIVEIRA, E. N., CUNHA, I. C. K., \& LEITE, J. L. Análise da produção do cuidado desenvolvido pelo enfermeiro na atenção à criança e ao adolescente vítima de violência doméstica. Sanare, v. 12, n. 1, p. 20-26, 2013. 